\title{
Study on Water Exchange and Water Quality Simulation of Macao Airport Expansion Project
}

\author{
Huang Pengfei ${ }^{1 *}$, Liu $\mathrm{Pei}^{1}, \mathrm{Xu} \mathrm{Wei}^{1}$ \\ ${ }^{1}$ Department of River \& Coastal Engineering of The Pearl River Hydraulic Research Institute, Guangzhou, Guangdong, 510098, China
}

\begin{abstract}
In this paper, we analyzed the current situation of water pollution sources near Macao airport, established a two-dimensional water exchange and water quality mathematical model near the project, and compared and simulated the reclamation schemes of Macao airport. According to the results of water exchange and COD calculation of water quality, the $80 \mathrm{~m}$ channel scheme was remarkably better than the $40 \mathrm{~m}$ one in terms of water exchange capacity and the possibility of achieving the water quality target. However, with the increase of channel width, the variation of water exchange rate and half exchange period would slow down. There was no significant difference in water exchange rate, water exchange period and water quality distribution between $80 \mathrm{~m}$ channel and $120 \mathrm{~m}$ channel. The final scheme was to adopt the $80 \mathrm{~m}$ channel.
\end{abstract}

\section{Engineering general situation}

The building of Macau International Airport was officially started in 1989 and completed in 1995. It is composed of runway artificial island, parking apron, terminal building and two taxiing bridges connecting artificial island and the apron. In 2016, the airport witnessed 57000 aircraft movements and 6.63 million passengers. At present, some facilities have been saturated, such as commercial aviation facilities, passenger terminal buildings and land transport facilities, while other facilities, like the parking apron, will be inadequate one after another. Therefore, in order to ensure aviation safety and meet the requirements of Aviation Convention, based on the Overall Development Plan of Macao International Airport, the north and south ends of the runway artificial island and the west side of the airport will be reclaimed, so as to ensure the safety zone at the end of the runway and drive the development of the airport. The project location is shown in Figure 1.

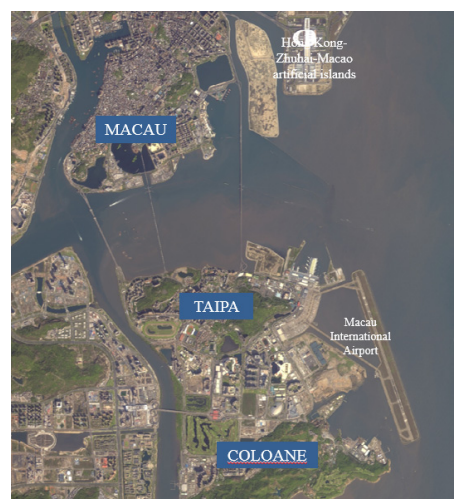

Figure 1 Geographical location of Macao Airport
The reclamation in the triangle area on the west of the airport runway artificial island will change the current connection between the upstream and downstream, and may have adverse effects on the ecological environment of the surrounding waters and the drainage of the land area on the west side of the airport. Therefore, on the basis of full consideration of the land conditions and expansion needs of the waters around the airport, the comparison and selection of airport expansion schemes are carried out from the perspective of protecting the water ecological environment.

\section{Current water environment near the airport}

The water quality near Macao airport is not only affected by the upstream and downstream water and the tail water discharged from the nearby sewage treatment plant, but also affected by the domestic sewage, factory waste water and initial rainwater discharge in surrounding land.

(1) Domestic sewage

The main sources of domestic sewage in the western waters of the airport runway are Jiuao village, Luhuan power plant and the Container terminal. The domestic sewage from Jiuao village and the Container terminal is directly discharged into the sea, and the sewage from workers in Luhuan power plant is discharged after being treated by the sewage treatment equipment of the power plant. Domestic sewage carries such features as small quantity, low water quality and continual discharge, directly affecting the water environment of Jiuao Bay.

(2) Factory waste water 
Luhuan power plant consists of the two plants, named CCA and CCB. There are 8 units in CCA plant. The designed total discharge from G01 to G04 units is $10230 \mathrm{~m}^{3} / \mathrm{h}\left(2.8 \mathrm{~m}^{3} / \mathrm{s}\right)$; the designed total discharge from G05 to G08 units is $12427.8 \mathrm{~m}^{3} / \mathrm{h}\left(3.5 \mathrm{~m}^{3} / \mathrm{s}\right)$. The CCB plant is $12427.8 \mathrm{~m}^{3} / \mathrm{h}\left(3.5 \mathrm{~m}^{3} / \mathrm{s}\right)$. The discharge of Luhuan power plant is relatively large, and its water quality has a certain impact on the water quality of Jiuao Bay.

(3) Initial rainwater

Surface runoff contains a considerable amount of suspended particles, nutrients, heavy metals and organic pollutants, which are discharged into the receiving water without treatment, easily leading to eutrophication and affect the water environment in the area. According to the data of Macao airport drainage network and the investigation on site, the rainwater entering the west water area of the airport runway mainly comes from the west residential areas of the runway, Macao airport, Luhuan power plant, Jiuao village and the Container terminal. In addition, there are about $0.96 \mathrm{~km}^{2}$ of landfills near the south side of airport apron, which may produce some pollution in the Bay in the early rain spell. The high load pollution and the large quantity in a short time make the initial rainwater become the potential risk of water environmental pollution in the west water area of the runway.

According to the water quality monitoring of each drainage outlet in December 2017, it is found that the input of land-based sources of pollution in the surrounding waters of Macao airport is mainly $\mathrm{pH}$, ammonia nitrogen, total nitrogen and total phosphorus. Among them, the ammonia nitrogen in the drainage ditch of Jiuao village exceeds the Class V of the National Surface Water Quality Standards (GB3636-2002), and the maximum extra standard reaches 10.5 , represents the serious land-based sources of pollution.

\section{Mathematical model of water quality for water exchange}

\subsection{Model Construction}

The two-dimensional tidal current mathematical model of the Pearl River estuary is used to provide the flow and tide process boundary for the local model of the waters near Macao. The project adopts the hydrological boundary conditions of the whole tide combination in dry season (including the middle, high and low tides in the fortnightly tide), the flow rate boundary uses the measured data collected from Maliuzhou hydrological station, and the specific boundary of water level is extracted from the Pearl River estuary model of the Pearl River Hydraulic Research Institution.

The research scope of the model is indicated in figure 2. The research area of the model is divided into 475059 rectangular grids, and the key research areas near the project, such as Jiuao Bay, the triangle area of the airport and water area near the airport, are refined. The minimum size of the grid is $5 \mathrm{~m}$.

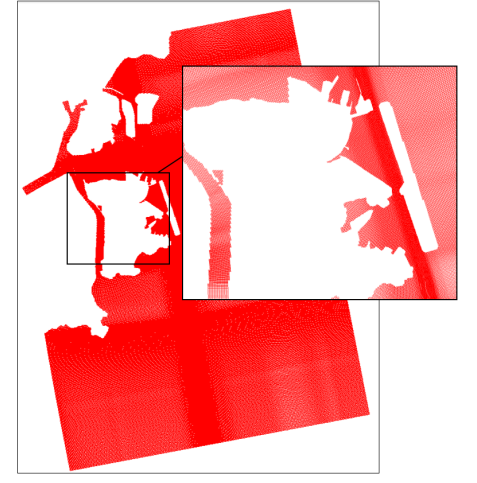

Figure 2 Scope of water quality mathematical model in the waters near Macao

\subsection{Study on water exchange}

\subsubsection{Analysis method}

Water exchange capacity serves as an important index of water environmental capacity and a significant factor affecting the distribution characteristics of water quality. The mathematical model uses the water quality point tracking method to calculate the water exchange in Jiuao Bay. The main calculation principle is as follows: Taking the soluble conservative material as tracer, the law of material concentration change caused by fluctuation current is calculated by plane twodimensional model and then analyze the result. The initial condition of the model calculation: the initial concentration of conservative tracer in Jiuao Bay is assumed to be $1 \mathrm{mg} / \mathrm{L}$. And the initial concentration of other regions in the model is set as $0 \mathrm{mg} / \mathrm{L}$.

\subsubsection{Water exchange characteristics in Jiuao Bay}

The weakest water exchange capacity of Jiuao Bay presents under the implementation of full reclamation scheme, and the capacity enhances gradually with the increase of the channel width in the triangle area. The concentration distribution of tracer at typical time (flood slack and the lowest tide) is selected for comparison, as shown in figure 3. Under the influence of different schemes with various hydrodynamics, from the full reclamation scheme to the present situation, the overall tracer concentration at the same time decreases with the increase of the channel width in the triangle area. For the time of flood slack and the lowest tide, except for the full reclamation scheme, the tracer of the other schemes trace back to the triangle area to varying degrees with the rising tide, and most of the tracers are not flow northward into the Macao channel; for the lowest tidal time, the $40 \mathrm{~m}$ scheme in the northern part of the Bay demonstrates obviously weaker capacity than that of the $80 \mathrm{~m}$ scheme, the $120 \mathrm{~m}$ scheme and the current situation. And the channel width of the $40 \mathrm{~m}$ scheme is not enough to support the tracer flow into the open sea in one tidal cycle, which may pose risks to the water exchange in the Bay. 
Figure 3 shows the pollutant distribution at typical time under the scheme of retaining $40 \mathrm{~m}$ and $80 \mathrm{~m}$ channel width. It can be seen that after the implementation of $80 \mathrm{~m}$ scheme, the concentration (color) of pollutants in Jiuao Bay at each typical time is significantly higher than that of $40 \mathrm{~m}$ scheme. Consequently, the water exchange of $80 \mathrm{~m}$ scheme is better than that of $40 \mathrm{~m}$ scheme.

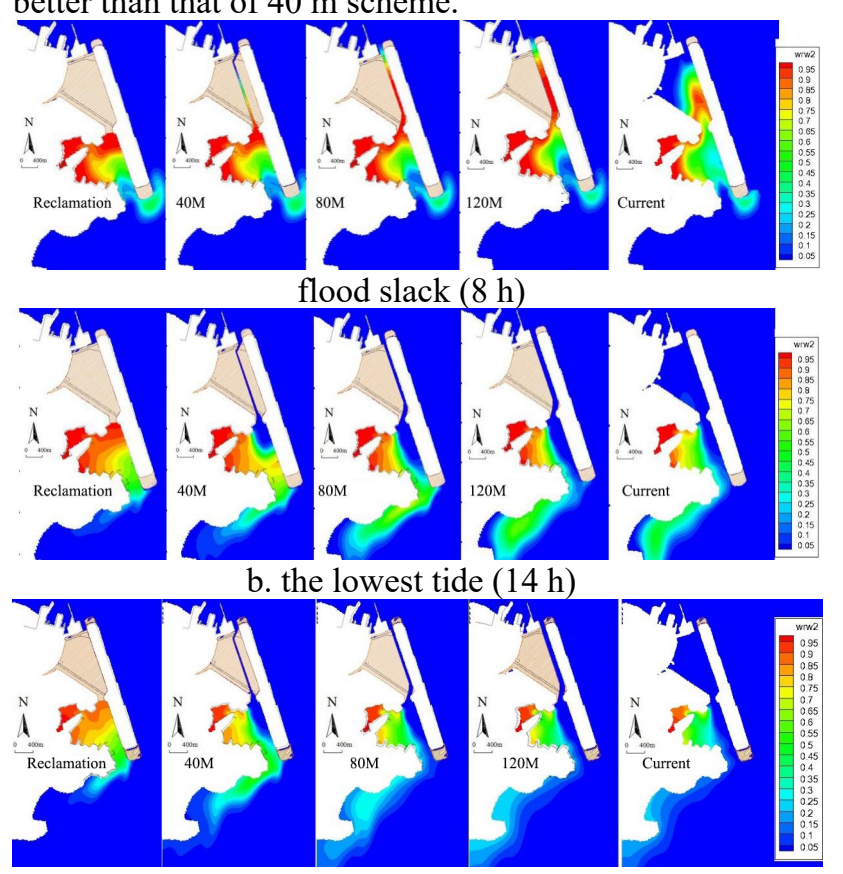

c. the lowest tide $(27 \mathrm{~h})$

Figure 3 Tracer concentration distribution at typical time in Jiuao Bay

\subsection{Water quality variation analysis}

\subsubsection{Pollution distribution considerations}

The water quality simulation considers that there are several sewage treatment plants in the sea area near Macao, especially the sewage discharge from Dangzai sewage treatment plant near the airport and Macao Peninsula sewage treatment plant have produced significant impacts on the water area near the airport, so the sewage discharge from the sewage treatment plant is considered in the water quality simulation.

Based on the analysis of the current situation of the water environment near the airport and the analysis of the initial rain pollution caused by 20 years' rainstorm near the airport, the domestic sewage and the initial rain pollution around the Jiuao Bay are also simulated. This is helpful to more accurately simulate the water quality of the water area near the project under the current conditions.

\subsubsection{Characteristics of water quality change}

After the implementation of each scheme, it can be seen from the COD distribution nephogram (Figure 4) that after 12 hours of rainfall, the differences among the schemes are not obvious; after 36 hours, the differences among the current scheme, $80 \mathrm{~m}$ scheme and $120 \mathrm{~m}$ scheme are weakened in the main channel area of Jiuao Bay, but the $40 \mathrm{~m}$ scheme still witnesses the Class IV water in a certain area in the south side of the channel area, and the differences between the $40 \mathrm{~m}$ scheme and other schemes are obvious; after 72 hours, with the $80 \mathrm{~m}$ and $120 \mathrm{~m}$ and the current schemes, only $30 \%$ or so of north power plant belong to Class IV water, while the whole area of the $40 \mathrm{~m}$ scheme belongs to Class IV water.

On the whole, the $80 \mathrm{~m}$ and $120 \mathrm{~m}$ channel schemes carry strong tide flow, which can meet the demand that the tracer can flow into the open sea in an ebb tide period, while the $40 \mathrm{~m}$ fails to make it. At the same time, the COD concentration of the $40 \mathrm{~m}$ scheme is significantly higher than that of other schemes, and there is a greater risk of pollutant transport in the cecum section of the north bay of the power plant. The overall difference of pollutant distribution between $80 \mathrm{~m}$ and $120 \mathrm{~m}$ schemes is small.

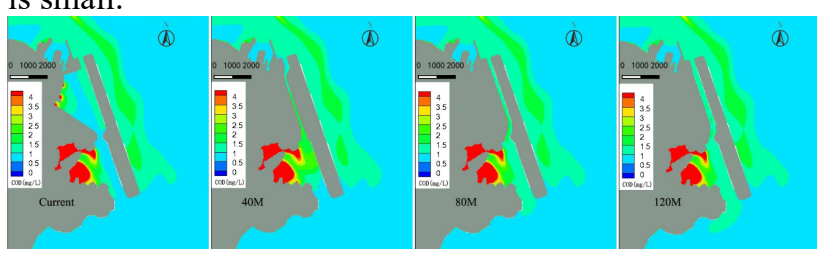

a. COD distribution nephogram of each scheme in $12 \mathrm{~h}$

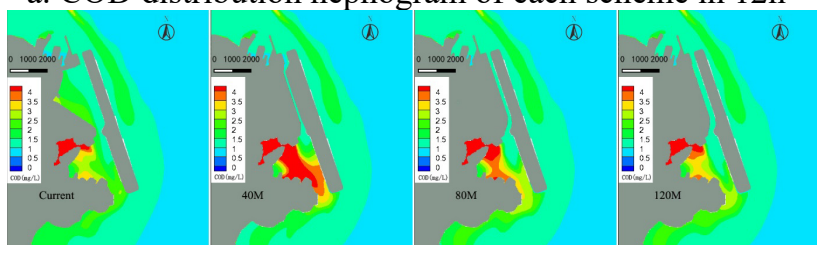

b. COD distribution nephogram of each scheme in $36 \mathrm{~h}$

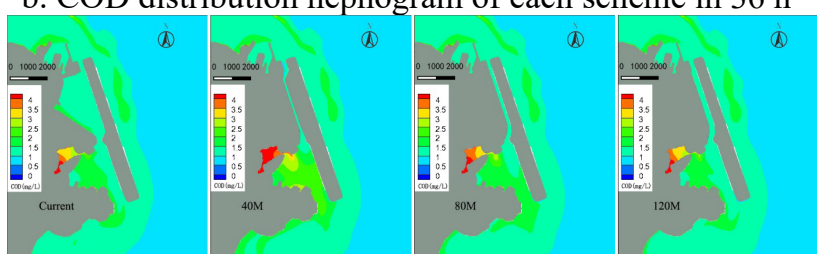

c. COD distribution nephogram of each scheme in $72 \mathrm{~h}$

Figure 4 COD distribution nephogram of each scheme

Through mathematical model calculation and physical model test, in this section, we predict the water exchange capacity of Jiuao Bay after the implementation of four expansion schemes, including full reclamation, reserved channel width of $40 \mathrm{~m}, 80 \mathrm{~m}$ and $120 \mathrm{~m}$ respectively in the western triangle area of runway. On this basis, combined with the water quality distribution status and pollution sources of surrounding waters, the water quality distribution characteristics and potential water quality of the Bay after the implementation of different schemes are studied and analyzed. Meanwhile, we compare the effects of different channel schemes on the drainage capacity of the airport and draw the following conclusions:

(1) The increasing channel width gives rise to the enhancing water exchange capacity in Jiuao Bay. After the implementation of the full reclamation scheme, $40 \mathrm{~m}$, 
$80 \mathrm{~m}$ and $120 \mathrm{~m}$ channel scheme, the half exchange period of the water in the Bay is $66.4 \mathrm{~h}, 30.5 \mathrm{~h}, 18.0 \mathrm{~h}$ and $16.7 \mathrm{~h}$ respectively. The water exchange rate reaches $47.7 \%, 67.4 \%, 80.2 \%$ and $85.4 \%$ respectively after two days. After the full reclamation of the triangle area, the half exchange period of the water is 4.2 times of the current situation, and the exchange rate of water only reaches $54 \%$ after two days.

(2) With the increase of channel width, the water exchange rate and half exchange period tends to be stable. In terms of water exchange rate, there is a difference of $5.2 \%$ of the water exchange rate between $80 \mathrm{~m}$ and $120 \mathrm{~m}$ scheme with the equal width, and that of $40 \mathrm{~m}$ and $80 \mathrm{~m}$ scheme is $12.8 \%$. In terms of half exchange period, the $40 \mathrm{~m}$ channel scheme is 1.9 times of the current situation, and the $80 \mathrm{~m}$ channel scheme is close to the $120 \mathrm{~m}$ channel scheme.

(3) Compared with the channel area and south area, the north area of the power plant has the worst hydrodynamic performance and the weakest water exchange capacity. After the implementation of each scheme, the half exchange period of water in north area reaches more than $60 \mathrm{~h}$, of which the full reclamation scheme is over $150 \mathrm{~h}$. Under the scheme of $40 \mathrm{~m}$ channel, only $12 \%$ water are exchanged in the north area two days later, and the water exchange rate is reduced by nearly $60 \%$ compared with the current situation.

(4) The channel width of $40 \mathrm{~m}$ fails to support the flowing of the tracer in a tidal cycle. In each time period, the Class IV water in the $40 \mathrm{~m}$ scheme is significantly larger than that in the $80 \mathrm{~m}$ and $120 \mathrm{~m}$ schemes.

After the implementation of the full reclamation, the hydrodynamic performance and water exchange capacity of Jiuao Bay is significantly weakened. The channel width of $40 \mathrm{~m}$ scheme is not enough to support the flowing of the tracer in a tidal cycle. The water exchange capacity in Jiuao Bay is insufficient and the water quality risk is high.

\section{Conclusion}

Whether from the water exchange capacity in Jiuao Bay or the possibility of achieving water quality, the $80 \mathrm{~m}$ channel scheme is far better than the $40 \mathrm{~m}$. However, with the increase of channel width, the variation of water exchange rate and half exchange period will slow down. There is little difference between the $80 \mathrm{~m}$ channel scheme and $120 \mathrm{~m}$ channel scheme in terms of water exchange rate, exchange period and water quality distribution characteristics.

Therefore, considering the impact of the implementation of the project on the water environment of Jiuao Bay and the drainage safety of its own land area, the width of the reserved channel in the west triangle area of the runway is recommended to be $80 \mathrm{~m}$.

\section{References}

1. Resources \& Hydraulic Engineering Iahr-apd Congress \& Symposium of Iahr-ishs. 2009.
2. Chang Ze, Zhang Qionghai, Jiang Yu, Sun Ning, He Rui, Wang Tengfei, Wu Yaju, Long Xiaofei. An analysis of the impact of sewage outlet on water quality of Macao coastal waters based on MIKE21 Model [J]. Pearl River, 2021, 42 (03): 70-80.

3. Zhang Xueqing, Sunyinglan, Cai Huiwen, etc. Numerical simulation on concentration of pollutant COD, $\mathrm{N}$ and $\mathrm{P}$ in Jiaozhou Bay [J]. Marine Environmental Science, 2005, 24 (3): 64-67.

4. Gan Jianjun, Li Can. Numerical simulation of hydrodynamics of ecological water transfer in the artificial lake based on MIKE21 [J]. Pearl River Water Transport, 2019, 000 (019): 28-29.

5. Chen Wenlong, Zou Huazhi, Dong Yanjun. Upstream hydrodynamics characteristics analysis of salt tide in Modaomen waterway, Advances in Water Science, 2014, 25 (05): 713-723.

6. $\mathrm{Xu}$ Hui. Numerical study on the impact of Sanjiankou Reclamation in Wenzhou on costal hydrodynamics [D]. Dalian University of Technology, 2020.

7. Shi Juan, Li Ruijie, Chen Peng, Sha Yuanhong, Li Yuting. Numerical simulation of Tongzhou Bay reclamation project and its influence $[\mathrm{J}]$. Port \& Waterway Engineering, 2017 (04): 20-27. 